\title{
Educação Financeira na Escola: A perspectiva da Organização para Cooperação e Desenvolvimento Econômico
}

\author{
Amarildo Melchiades da Silva \\ Universidade Federal de Juiz de Fora, Brasil \\ Departamento de Matemática \\ amarildo.melchiades@ufjf.edu.br
}

\section{Arthur Belford Powell}

Rutgers University - Newark, USA

Departamento de Educação Urbana

powellab@andromeda.rutgers.edu

\section{Resumo}

O presente artigo apresenta uma revisão da literatura da proposição e implementação de um projeto de educação financeira desenvolvido pela Organização para Cooperação e Desenvolvimento Econômico (OCDE) que envolveu seus países membros e países não-membros. A revisão foi feita a partir dos documentos e informações disponibilizados virtualmente pela OCDE no período de 2003 a 2012 e teve como objetivo investigar a proposta da organização de educar financeiramente os cidadãos dos países membros e de levar o assunto para a escola. Este estudo foi o ponto de partida de uma investigação mais ampla que teve como finalidade analisar as possibilidades de inserção dessa temática no currículo de matemática das escolas públicas brasileiras como parte da educação matemática dos estudantes da Educação Básica.

Palavras-chave: Educação Matemática. Educação Financeira Escolar. Literacia Financeira. OCDE. Educação Básica.

\section{Financial Education in Schools: The perspective of the Organization for Economic Cooperation and Development}

\begin{abstract}
This article presents a literature review of the proposition and implementation of a financial education Project developed by the Organization for Economic Cooperation and Development (OECD) that involves both its member countries and some non-member countries. The review is based on documents and information provided virtually by the OECD in the period from 2003 to 2012 and aimed to investigate the organization's proposal to educate financially citizens of member countries and to take the matter to schools. This study is a starting point of a broader investigation that aims to analyze how to insert financial education into the mathematics curriculum of Brazilian public schools for student of Basic Education.
\end{abstract}

Keywords: Mathematics Education. School Financial Education. Financial Literacy. OECD. Elementary and Secondary Education. 


\section{Introdução}

Este artigo é fruto de uma pesquisa intitulada Uma experiência de Design em Educação Matemática: O projeto Educação financeira escolar ${ }^{1}$, cujo objetivo foi investigar, em nível teórico, uma proposta de inserção da Educação Financeira no currículo de matemática das escolas públicas brasileiras como parte da educação matemática dos estudantes da Educação Básica.

As investigações sobre Educação Financeira Escolar e sua inserção no currículo de matemática é uma frente nova e fértil de pesquisa em Educação Matemática. Como veremos ao longo deste artigo, as propostas existentes de se levar o assunto para o currículo escolar sugere que ele pode ser discutido em diferentes disciplinas da Educação Básica. Assim, nossa perspectiva foi analisá-lo, na pesquisa acima citada, como um tema transversal ao currículo de matemática e que perpasse outras áreas de conhecimento.

A preocupação com o ensino de Educação Financeira nas escolas e a necessidade de se pensar a formação de professores para este fim foram os dois pontos que motivaram originalmente nossa pesquisa. A revisão da literatura inicial evidenciou a urgência de se sugerir uma proposta de Educação Financeira para a realidade brasileira e a importância de formar professores para atender a esta demanda nas escolas visto que, em muitos casos, não são professores os profissionais que têm cuidado da formação dos estudantes nos países que introduziram a Educação Financeira no ambiente escolar. Além disso, o currículo existente não foi construído apenas para atender aos interesses da escola, mas para atender também a outros interesses, como os das instituições financeiras interessadas em formar futuros consumidores para seus produtos financeiros.

O presente artigo apresenta uma revisão da literatura sobre os estudos, recomendações e iniciativas da Organização para Cooperação e Desenvolvimento Econômico (OCDE) sobre o tema, em que a coleta de dados foi feita considerando os documentos disponibilizados pela organização e por algumas outras entidades internacionais envolvidas em levar o assunto para as escolas das diferentes nações.

Nosso foco esteve em analisar as pesquisas desenvolvidas pela Organização devido à abrangência do estudo e o alcance de suas recomendações direcionadas a seus 34 países membros e aos países não membros convidados a participarem do projeto, como, por exemplo, o Brasil.

Outras organizações influentes no mundo financeiro, como o Banco Mundial e o Fundo Monetário Internacional (FMI), também estiveram envolvidas na proposta de educar financeiramente os cidadãos de diferentes países. Essa participação foi desde a recomendação em seus relatórios técnicos sobre estratégias para tornar o mercado mundial mais saudável com respeito, por exemplo, à transferência de riscos dos setores bancários para outros setores da

\footnotetext{
${ }^{1}$ Projeto de Pesquisa financiado pela Capes
} 
sociedade incluindo, em especial, a preocupação com a transferência de riscos para o núcleo familiar (cf. IMF, 2005), até o apoio financeiro para o estudo do impacto de programas de Educação Financeira em diferentes países (cf. WORLD BANK, 2012). Nosso interesse, porém, está no projeto de Educação Financeira da OCDE que entrou na pauta dos assuntos da Organização a partir do ano de 2003.

Assim, nosso ponto de partida foi analisar os documentos da Organização disponibilizados a partir de suas pesquisas e suas ações posteriores com o objetivo de se desenvolver um programa de educação financeira para seus países membros.

Nossa análise dos relatórios e documentos da OCDE buscou reunir elementos para pensar os caminhos para um curso de formação de estudantes da Educação Básica no Brasil. Portanto, não tivemos interesse em analisar temas como os processos de avaliação em larga escala da organização, a não ser quando estes nos ajudaram a elucidar as concepções de educação financeira da própria organização.

\section{Os Estudos e Recomendações da Organização: Uma visão Geral}

O programa de trabalho da OCDE, aprovado pelo seu conselho para o biênio 2003-2004, incluiu um projeto intitulado Financial Education Project que deveria ser desenvolvido por dois de seus Comitês: a Comissão de Mercados Financeiros e de Seguros e a Comissão de Pensões Privadas. O projeto nasceu, segundo consta nos documentos da organização, do interesse dos países membros em educar financeiramente seus cidadãos.

Como parte do desenvolvimento desse projeto, aconteceu o primeiro grande estudo sobre o tema em nível internacional, que foi implementado em duas fases. A primeira fase teve como foco a população em geral; seu objetivo foi identificar e analisar pesquisas sobre Educação Financeira nos países membros da OCDE, descrever os diferentes tipos de programas existentes sobre o tema que estavam sendo oferecidos na época e avaliar, na medida do possível, sua eficácia. O resultado do estudo deveria fornecer informações e sugerir ações aos formuladores de políticas dos países para que eles pudessem melhorar a educação financeira e a conscientização de seus cidadãos. A segunda fase da pesquisa foi direcionada para descrever e analisar programas de Educação Financeira nas escolas e universidades.

A primeira fase do projeto culminou, em 2005, com a publicação da pesquisa registrada em um relatório intitulado Improving Financial Literacy ${ }^{2}$ : Analysis of Issues and Policie ${ }^{3}$. (Cf. OECD, 2005a)

\footnotetext{
${ }^{2}$ Financial Literacy será traduzido, neste artigo, como Literacia Financeira.

${ }^{3}$ Em português: Melhoria da Literacia Financeira: Análise de Questões e Políticas.
} 
A coleta das informações desenvolvida na pesquisa permitiu identificar três grupos de consumidores vulneráveis no cenário financeiro que deveriam ser objeto de atenção dos governantes dos países membros da OCDE, a saber: os trabalhadores que necessitariam contar com suas pensões e suas economias pessoais para financiar sua aposentadoria; os consumidores endividados, em particular os jovens; um número significativo de consumidores que não participavam do sistema financeiro. (OECD, 2005a)

O relatório sinalizou como preocupante a falta de conscientização dos trabalhadores sobre a importância de poupar para a aposentadoria. Pesquisas desenvolvidas na época indicaram que quatro entre dez trabalhadores estadunidenses não estavam poupando para a aposentadoria e, entre os neozelandeses, muitos não queriam, ou não se sentiam capazes de poupar o suficiente para a aposentadoria.

Outro grupo de consumidores que mereceriam a atenção dos governos dos diferentes países era os consumidores endividados. Segundo o relatório, o motivo residia, em geral, no aumento do empréstimo hipotecário, no uso indevido do cartão de crédito e nos empréstimos predatórios a que as pessoas se submetiam e que resultavam em endividamento excessivo, no aumento da inadimplência de crédito e em falências pessoais. Isso indicava que a inabilidade na gestão do dinheiro, o desconhecimento de questões financeiras e as condições adversas poderiam gerar efeitos catastróficos nas finanças pessoais e familiares.

O terceiro grupo de consumidores, que deveriam ter a atenção dos governos, de acordo com o relatório, seria aqueles afetados pela exclusão financeira, as pessoas de baixa renda e os analfabetos financeiros. Sobre esses últimos, o relatório comenta:

O analfabetismo financeiro pode ter grande impacto sobre indivíduos e famílias na gestão
diária de seus recursos, minando, por exemplo, sua capacidade de investir em questões-
chave de longo prazo (como educação superior, financiamento habitacional, aposentadoria),
ou, ainda pior, expondo-os a graves problemas econômicos. (OECD, 2005a, p. 76)

Em países como a Austrália, o Canadá, o Reino Unido e os Estados Unidos, a população carente e sem conta bancária era composta por consumidores de baixa renda, minorias étnicas e raciais, imigrantes, refugiados e indígenas.

A importância do tema Educação Financeira foi mencionada no relatório como decorrente da evolução e sofisticação dos mercados financeiros e das mudanças demográfícas, econômicas e políticas dos últimos tempos. Nessa direção, o estudo evidenciou vários fatores que aumentavam essa importância para os países membros da OCDE. Entre eles estavam: i) o baixo nível de conhecimento financeiro dos consumidores, em particular, na camada da sociedade constituída pelos menos instruídos, por aqueles que pertenciam às minorias étnicas e raciais e por aqueles que estavam na extremidade inferior da distribuição de renda; ii) o aumento e a complexidade dos 
produtos financeiros; iii) o aumento da expectativa de vida das pessoas e as mudanças no regime de pensão.

Sobre este último fator, o relatório chamava a atenção para as reformas nos regimes de pensões ocorridas em vários países e muitas vezes impostas à população, surgindo assim à necessidade de as pessoas receberem informações básicas sobre essas mudanças. Como consequência, um número crescente de trabalhadores precisaria assumir a responsabilidade de cuidar de suas aposentadorias, pois estava ocorrendo, em alguns países, a transferência dessa responsabilidade do empregador para o empregado.

Além desses fatores que sugeriam a importância de educar financeiramente a população, o relatório indicou que a maioria dos países membros da OCDE estava oferecendo programas de Educação Financeira em uma ampla variedade de temas, tais como: crédito, seguro de investimentos e pensões. Essas informações eram dirigidas ao público em geral. Porém alguns programas estavam direcionados, mais especificamente, aos investidores, aos consumidores endividados e às pessoas que estavam fora do sistema financeiro.

Uma parte importante do estudo tratou da avaliação da literacia financeira dos consumidores, com a perspectiva de que essas pesquisas pudessem orientar os governos na identificação de habilidades e conhecimentos financeiros que faltariam a essas pessoas. Como consequência, seria possível ter um parâmetro para medir a literacia financeira das pessoas e permitir avaliar a eficácia dos programas de Educação Financeira.

A OCDE selecionou para análise as pesquisas sobre literacia financeira desenvolvida na Austrália, Japão, Coréia do Sul, Estados Unidos e Reino Unido, considerando o fato de que, nesses estudos, existia informação detalhada sobre metodologia, público alvo e resultados.

$\mathrm{O}$ estudo indicou que, apesar da diferença entre as pesquisas desenvolvidas nos diferentes países com respeito a, por exemplo, público-alvo e metodologia de pesquisa, foi possível observar alguma semelhança nos resultados das pesquisas.

Um resultado comum em todas as pesquisas nos diferentes países revelou o baixo nível de compreensão financeira entre os respondentes. Constatou-se que os níveis de educação e renda dos pesquisados não estava relacionado a uma melhor educação financeira; pois "consumidores com alto nível educacional e de renda podem ser tão ignorantes sobre questões financeiras quanto aqueles de nível mais baixo". (OCDE, 2005a, p.91)

O segundo resultado comum observado foi que os consumidores acreditavam saber mais sobre questões financeiras do que realmente sabiam. A consequência dessa conduta seria a de que este entendimento poderia levá-los a futuros problemas financeiros visto que, ao não perceberem que precisavam de informação, não se empenhariam para obtê-la. 
O terceiro resultado comum detectado foi que, em diferentes países, os consumidores possuíam dificuldades em encontrar e compreender informações financeiras. A pesquisa com consumidores japoneses, por exemplo, revelou que os entrevistados sentiram-se frustrados com a dificuldade em encontrar e compreender informações financeiras. A pesquisa com consumidores britânicos descobriu que eles não procuravam ativamente informações financeiras e aquelas informações que recebiam eram adquiridas por sorte ou por acaso, através de um panfleto de banco, ou quando tinham oportunidade de falar com um funcionário do banco.

O quarto resultado comum indicou que aconteceram poucas avaliações de programas de Educação Financeira para determinar o que funcionou bem, ou não. Entendeu-se que isso era devido aos altos custos de uma avaliação e dos orçamentos limitados dos governos.

O estudo indicou ainda os possíveis benefícios que a Educação Financeira poderia proporcionar aos diferentes grupos de pessoas. Por exemplo, aos jovens adultos que começam sua vida profissional poderia fornecer as ferramentas básicas para manterem seu orçamento e economias sobre controle; para as famílias, poderia proporcionar disciplina em poupar com o objetivo de comprar a casa própria ou poupar para a educação dos filhos; para os trabalhadores, poderia ajudá-los na programação de uma aposentadoria confortável, fornecer informações e habilidades para fazer bons investimentos e fazer boas escolhas em planos de pensão e planos de poupança individuais. Além disso, poderia ajudar também as pessoas de baixa renda a pouparem e a evitarem gastos com altos custos em transações financeiras. E para aquelas pessoas com dinheiro para investir, a educação financeira poderia proporcionar maior compreensão de informações financeiras básicas para fazer boas transações.

Sobre os benefícios de se educarem financeiramente os cidadãos, é importante mencionar que as vantagens não seriam apenas para as pessoas comuns, mas também para a economia dos países que receberia um impacto significativo delas; esse fato não fica explícito nos relatórios da OCDE. (cf. COMMONWEALTH BANK FOUNDATION, 2004)

Portanto, este estudo nos sugere que o projeto de Educação Financeira proposto pela OCDE visava, a nosso ver, não só atender aos cidadãos, mas também melhorar a economia dos países membros.

Este foi o resultado da primeira fase do projeto de Educação Financeira da OCDE. Como consequência do relatório, os governos filiados à OCDE aprovaram um documento intitulado Recomendações sobre Princípios e Boas Práticas de Educação Financeira e Conscientização que tinha como objetivo sugerir aos governos ações e boas práticas para implementação em seus países. (OECD, 2005b) 
Nesse documento encontramos as definições de Educação Financeira e Literacia Financeira elaboradas para orientar as construções dos programas e das avaliações propostas pela organização, nos seguintes termos:

Educação Financeira é o processo pelo qual consumidores e investidores aprimoram seu entendimento em relação a conceitos e produtos financeiros, e, alicerçados em informação, instrução e/ou consultoria direta, desenvolvem habilidades e confiança que os torna conscientes das oportunidades e riscos financeiros, para fazer escolhas informadas, mais capazes de obter informação adicional para fazer escolhas, saberem onde buscar ajuda e de assumirem outras ações efetivas a fim de melhorar a sua proteção e o seu bem-estar financeiro. (OECD, 2005a, p. 26)

Esta definição foi posteriormente adotada por alguns países na orientação de sua proposta de Educação Financeira como, por exemplo, a Espanha (Cf. CNMV/BANCO DE ESPAÑA, 2008) e o Brasil (BRASIL, 2011, p.57-58).

A OCDE/INFE passou então a utilizar duas definições de Literacia Financeira em seus programas e metodologias de avaliação, uma para adultos e outra para jovens. Para a população adulta um teste piloto para medição de Literacia Financeira adotou a seguinte definição:

Literacia financeira é uma combinação de consciência, conhecimento, habilidade, atitude e comportamento necessários para tomar consistentes decisões financeiras e alcançar almejado bem-estar financeiro individual. (EIOPA, 2011, p.10)

Considerando esta definição, um questionário foi elaborado com o foco em três componentes: níveis de conhecimento financeiro, comportamento financeiro e atitudes relacionadas com vários aspectos da literacia financeira. Pois, segundo a proposta de avaliação, uma pessoa financeiramente alfabetizada deveria ter algum conhecimento básico de conceitos financeiros fundamentais, e a maneira como as pessoas se comportam e as atitudes e preferências que possuem teriam um impacto significativo sobre o seu bem-estar financeiro.

A outra definição foi formulada por um grupo de peritos, que desenvolveu a avaliação para o PISA 2012 que avaliou a Literacia Financeira dos estudantes a partir da seguinte definição de trabalho:

Literacia financeira é o conhecimento e entendimento de conceitos e riscos financeiros, e a habilidade, motivação e confiança em aplicar tal conhecimento e entendimento tomando decisões efetivas em vários contextos financeiros a fim de melhorar o bem-estar financeiro do indivíduo e da sociedade, e permitindo a participação na vida econômica (OECD, 2012, p.13).

O que o documento ressalta, através dessa definição, é que o foco da avaliação está em verificar a capacidade dos jovens em usar os seus conhecimentos e habilidades de modo a enfrentar os desafios de uma vida real para além da escolaridade obrigatória ao invés apenas de dominar o conteúdo curricular específico. Em outras palavras o documento afirma: 
fixa, uma fronteira que tem que ser cruzada, estando o analfabetismo de um lado e a alfabetização do outro. Literacia envolve mais do que a reprodução de conhecimento acumulado, apesar de que a mensuração do conhecimento financeiro prévio seja um elemento importante de avaliação. Ela também envolve a mobilização de aptidões cognitivas e práticas, assim como outros recursos como atitude, motivação e valores. $\mathrm{O}$ PISA 2012, avaliação de literacia financeira, baseia-se numa variedade de conhecimentos e habilidades associados com o desenvolvimento da capacidade de lidar com as exigências financeiras do dia a dia da sociedade contemporânea. (OECD, 2012, p.13)

As diferentes definições que, em geral, são apresentadas de Educação Financeira e Literacia Financeira nos ajudam a entender a perspectiva sobre o que se pretende com as propostas de educação financeira, seja na perspectiva da OCDE ou de outras organizações e instituições financeiras. Observamos que muitos programas buscam atender públicos alvos específicos como investidores, consumidores em geral, empresários e trabalhadores. Assim, o que vai diferenciar uma definição da outra será o tipo de formação que se pretende dar a esse público em especial.

No caso da OCDE, esses dois conceitos vão orientar os estudos desenvolvidos pela organização e pelos vários países participantes do projeto de Educação Financeira.

\section{Os Estudos e Recomendações da OCDE para a escola}

A segunda fase do projeto objetivou descrever e analisar programas de Educação Financeira disponíveis nas escolas e nas universidades dos países membros.

Ainda no ano de 2005, a organização publicou um segundo documento intitulado Recommendation on Principles and Good Practices For Financial Education and Awareness ${ }^{4}$ para orientar os governos em suas ações. Na seção "Boas Práticas”, do documento, encontramos a recomendação de que a Educação Financeira deveria começar na escola considerando o fato de que as pessoas deveriam ser educadas sobre questões financeiras o mais cedo possível em suas vidas. (OECD, 2005b). E, como consequência dessa perspectiva, o documento sugeria:

Para os programas que favoreçam o uso de sala de aula, devem ser promovidos cursos adequados e a capacitação dos educadores. Assim, precisam ser incentivados programas de "formação dos formadores", e a distribuição de material informativo específico e ferramentas para estes formadores. (OECD, 2005b, p.7)

Assim, a segunda fase do projeto da OCDE, esteve voltada para a escola e foi publicado em 2008, como um relatório cujo título era Financial Education Programmes in Schools: Analysis of selected Current Programmes and Literature Draft Recommendations for Best Practices ${ }^{5}$. (MUNDY, 2008)

O relatório de 2008 teve como objetivo analisar os programas de educação financeira existentes nas escolas e estabelecimentos de ensino e analisar as pesquisas disponíveis sobre a

\footnotetext{
${ }^{4}$ Em português: Recomendações sobre Princípios e Boas Práticas para a Educação e Conscientização financeira.

${ }^{5}$ Em português: Programas de Educação Financeira nas Escolas: Análise de Programas Selecionados Atuais e Literatura, Recomendações Preliminares de melhores práticas.
} 
eficácia das iniciativas sobre o assunto destinado a crianças e adolescentes em idade escolar em alguns dos países membros e países não membros da OCDE.

A importância de se oferecer Educação Financeira nas escolas foi sustentada no relatório considerando, em linhas gerais, com os seguintes argumentos: i) a formação no ambiente escolar possui o potencial de atender esse público alvo em quase a sua totalidade, o que não está assegurado quando se considera outros segmentos da população, como por exemplo, os adultos; ii) os jovens tendem a ser mais receptivos à educação do que pessoas mais velhas; iii) as crianças estão se tornando consumidores ativos, sendo que seus gastos podem impactar sobre as despesas de suas famílias; iv) muitos jovens estão gastando muito, por exemplo, com telefonia móvel; v) crianças e jovens estão sendo o público alvo da publicidade e do marketing; vi) estudantes mais velhos terão que considerar as implicações financeiras e tomar decisões sobre a continuidade de seus estudos; vii) Os jovens estão, cada vez mais, tomando decisões financeiras que podem influenciar no seu futuro, por exemplo, expondo-se ao risco de acumular dívidas significativas e são financeiramente menos capazes de gerenciar suas finanças do que os mais velhos (enfrentando atualmente maiores desafios financeiros do que a geração dos seus pais, quando estavam com a mesma idade); viii) muitos pais não possuem o conhecimento e a capacidade de gerenciar o próprio dinheiro e por esta razão não se encontram em condições de oferecer orientação efetiva a seus filhos. (MUNDY, 2008, p.58)

Sobre o objetivo de um programa de Educação Financeira na escola, o relatório observou que existia um consenso geral de que o propósito da educação financeira seria o de ajudar os estudantes a gerenciarem bem o seu dinheiro ao longo de suas vidas. Assim o entendimento era que essa formação envolvesse conhecimentos, habilidades, atitudes e comportamentos e não só informação. E ainda que, se os estudantes que recebessem uma formação com este propósito, deveriam se comportar em suas vidas de forma financeiramente capaz, caso contrário, à proposta não teria alcançado sua finalidade.

O relatório apresentou ainda alguns pontos importantes na direção de nossos interesses ao revisar as principais questões e desafios para a incorporação da Educação Financeira nas escolas.

A primeira questão que ficou evidente no estudo foi o desafio de se convencerem políticos e profissionais que tomam as decisões educacionais para os governos sobre a importância do assunto e sobre a necessidade de fornecimento de espaço no currículo escolar para sua inserção. Pois o que se constatou foi que a Educação Financeira deveria competir por espaço com outros temas alternativos já existentes como, por exemplo, Nutrição e Educação Sexual. (Cf. MUNDY, 2008, p.62).

A segunda questão que o estudo evidenciou foi a necessidade de se decidir se a educação financeira deveria ser obrigatória ou eletiva no currículo escolar. 
Sobre essa questão e sobre todas as outras questões discutidas no documento, a OCDE não apresentou uma posição, mas relatou o que vinha acontecendo nos países pesquisados. Os estudos feitos nesses países indicaram que, em alguns deles ou em seus estados, a Educação Financeira era obrigatória no currículo. Nos Estados Unidos, por exemplo, em 2008, três estados exigiam pelo menos um curso de finanças pessoais por um semestre letivo. Mas, de estado para estado, havia diferentes decisões sobre como levar este assunto ao currículo. De modo análogo, no Canadá a disciplina era obrigatória em algumas províncias e facultativa em outras.

O entendimento de que a Educação Financeira deveria ser obrigatória no currículo tinha como defesa o fato de ser a forma mais segura de garantir sua inclusão nos programas escolares, pois, caso contrário, o fato de os currículos já estarem cheios dificultaria assegurar um espaço reservado caso fosse eletiva.

Outra questão importante apresentada no relatório foi se a Educação Financeira deveria ser inserida na escola como uma disciplina autônoma ou, em vez disso, como parte de disciplinas já existentes.

Neste caso, novamente o documento indicou o que cada escolha poderia resultar. De fato, a vantagem de uma disciplina autônoma de Educação Financeira seria a possibilidade de dar maior destaque ao assunto. Por outro lado, a incorporação da temática em disciplinas já existentes poderia permitir que os temas financeiros fossem discutidos numa ampla variedade de contextos; isso implicaria em atrair o interesse dos estudantes e facilitar sua aprendizagem.

Os exemplos da incorporação do assunto em disciplinas já existentes no currículo incluíam, apenas para citar algumas possibilidades, a Matemática, a Economia, a Geografia e a História. Mundy (2008) mencionando a Matemática observou:

Em Matemática, problemas monetários podem oferecer um contexto no qual alunos receberiam lições sobre questões diretamente relacionadas. Por exemplo, estudantes avaliariam a publicidade de um perfume que teve seu preço reduzido. Poderia ser pedido a eles que calculem a porcentagem da redução, e o custo do mililitro. $\mathrm{O}$ anúncio também poderia suscitar discussões sobre o que é essencial e o que é supérfluo, e se produtos e serviços mesmo tendo tido redução de preço têm bom valor para o consumidor. (MUNDY, 2008, p. 69)

A quarta questão que o relatório mencionou dizia respeito à idade em que as crianças deveriam começar o processo de aprendizagem do assunto. Sobre isso, Mundy (2008) observou que alguns experts consideravam que o assunto deveria ser introduzido no começo de suas vidas escolares por ser a melhor maneira de influenciar o comportamento das crianças, enquanto suas mentes estavam mais abertas a novos conceitos. Porém, também consideravam que os programas deveriam refletir as capacidades e interesses das crianças na faixa etária em que estivessem.

A quinta questão mencionada no relatório externava uma preocupação sobre como poderia tornar a Educação Financeira um tema mais envolvente para os estudantes. Nessa direção 
observavam que o estudo de finanças, por exemplo, poderia se tornar um assunto complexo e mesmo para adultos poderia ser um tema maçante.

O que podemos observar é que estas questões são realmente pertinentes para todos os governos que pretendem introduzir o assunto no ambiente escolar, e acreditamos que as respostas serão encontradas não por força de lei imposta ao sistema escolar, mas pela busca de consenso entre todos os envolvidos sobre como e em quais condições se dará esse processo de inserção do assunto na escola.

Por último, a revisão da literatura presente no relatório de 2008 sobre a eficácia dos programas de Educação Financeira nas escolas, nos países pesquisados e em alguns estudos anteriores realizados, concluiu que o ensino do assunto estava tendo pouco impacto sobre os beneficiários.

As pesquisas sobre o impacto da formação de estudantes em Educação Financeira, segundo o relatório, vinham sendo desenvolvidas, em geral, com mais intensidade nas escolas que nas universidades e faculdades. Além disso, as dificuldades com essas pesquisas eram decorrentes de vários fatores, entre eles: o fato de que não havia acordo geral sobre o que seria um estudante educado financeiramente; o fato de que não havia consenso sobre o que deveria ser medido; o fato de os estudantes que participaram de programas em execução não participarem de avaliações posteriores; o fato de que os programas foram concebidos para influenciar comportamentos futuros em vez de comportamentos atuais.

Após o desenvolvimento dos dois estudos mencionados anteriormente como ponto de partida do Projeto de Educação Financeira iniciado pela organização, novas ações foram produzidas para sugerir aos governos a inserção do tema na escola como veremos a seguir.

\section{Diretrizes da OCDE para a Educação Financeira na Escola}

Em 2011, a Rede Internacional sobre Educação Financeira6 da OCDE publicou uma versão final do documento intitulado Guidelines on Financial Education at School and Guidance on Learning Framework7 com base no relatório preliminar elaborado em 2008 (Mundy, 2008), discutido na seção anterior. O relatório foi considerado um complemento àquele publicado em 2005, denominado Recomendações sobre Princípios e Boas Práticas de Educação Financeira e Consciência (OECD, 2005b).

\footnotetext{
${ }^{6}$ Esta rede, denominada em inglês por International Network on Financial Education/INFE, foi criada pela OCDE em 2008 para promover e facilitar a cooperação internacional entre os governos interessados em participar da proposta de inserção da Educação Financeira nos diferentes países.

${ }^{7}$ Em português: Diretrizes para a Educação Financeira na Escola e Orientação sobre o Quadro de Aprendizagem.
} 
O propósito das diretrizes foi oferecer orientações gerais aos decisores políticos dos países participantes para a introdução e desenvolvimento de programas eficientes de Educação Financeira nas escolas, que, levando em consideração a estrutura dos sistemas educativos em nível local, regional ou nacional, deveriam ser aplicáveis a programas escolares do jardim da infância até o final do ensino oficial.

As diretrizes reafirmaram a importância da Educação Financeira no cenário mundial explicitada em todos os relatórios da organização sobre o tema. Porém, nesse relatório, os peritos foram mais incisivos em afirmar a importância da inclusão da Educação Financeira no currículo escolar oficial. O principal argumento estava no fato de ser a maneira mais eficiente de levar o assunto, em larga escala, a toda uma geração de jovens e crianças, além de ser um caminho para incutir e fomentar comportamentos e uma cultura financeira mais sólida nos estudantes. Eles acreditavam ainda que esses jovens poderiam, no futuro, ser bons divulgadores de novos hábitos financeiros para o resto da população.

O significado dos termos Educação Financeira e Literacia Financeira foi assim caracterizado:

\begin{abstract}
O termo Educação Financeira na escola será nestas diretrizes para se referir ao ensino de conhecimento financeiro, de compreensão, capacidade, comportamentos, atitudes e valores que permitam aos alunos tomar decisões financeiras seguras e efetivas no seu dia a dia e quando eles se tornarem adultos. Literacia (ou capacidade) financeira será usada para referir-se ao resultado (nos alunos) dos programas educacionais. (OECD/INFE, 2011, p.3).
\end{abstract}

A proposta de inserção da Educação Financeira nos currículos escolares é explicitada no relatório como parte de uma estratégia nacional, nos seguintes termos:

O ideal seria que a educação financeira fosse integrada ao currículo escolar como parte de
uma estratégia nacional sobre essa questão, de modo que toda criança de um dado país ou
jurisdição seja exposta ao assunto na escola. A introdução da educação financeira deve ser
precedida de, e baseada em, uma avaliação e análise do estado e nível dessa educação
financeira oferecida por intermédio do currículo existente e o nível atual da literacia
financeira das crianças e jovens. (OECD/INFE, 2011, p.6).

Para se chegar a uma formação eficaz, o relatório sugere os tópicos que seriam mais comumente incluídos nos quadros de aprendizagem de Educação Financeira e que, portanto, deveriam ser abordados considerando o nível e idade escolar dos estudantes. São eles: dinheiro e transações; planejamento e gestão das finanças; riscos e recompensas; paisagem financeira. Esta última, incluindo temas como o direito dos consumidores e uma compreensão mais ampla dos sistemas financeiro, econômico e social. (OECD/INFE, 2011, p.6).

As diretrizes recomendavam ainda que a Educação Financeira fosse introduzida na escola como componente obrigatório e legal do currículo nacional dos países. Sugeria que essa inserção ocorresse, ou como uma disciplina autônoma, ou através de módulos, ou como fazendo parte de outras disciplinas já existentes, ou ainda como uma disciplina horizontal integrada a uma ampla 
gama de classes. Seu início deveria acontecer, de preferência, no jardim de infância e escolas primárias e durar até, pelo menos, o final do currículo oficial e, se possível, ser ensinado até o final do equivalente ao nosso Ensino Médio.

Sobre os atores que participariam da inserção do tema na escola, do seu desenvolvimento e manutenção, o documento sugeria que seria desejável a participação, de representantes do governo, de órgãos financeiros reguladores, dos sistemas educacionais, de instituições financeiras privadas, de associações sem fins lucrativos, de redes locais, de organizações internacionais, de professores, de pais e da comunidade.

Vale observar que o relatório preliminar de 2008 já fazia menção a condições para que as entidades participassem da proposta, nos seguintes termos:

Entidades envolvidas na oferta de educação financeira podem desempenhar diferentes papéis, desde o estabelecimento de exigências ou orientações até o provimento de materiais, ou disponibilizando pessoal treinado para ir às escolas ajudar no ensino dos alunos em classe. (MUNDY, 2008, p. 65)

Porém, com base na experiência internacional e nos estudos que foram desenvolvidos nos países analisados pela OCDE, é possível constatar que a oferta da Educação Financeira para a escola não tem colocado a proposição, nem a responsabilidade do seu ensino nos ministérios da Educação, nem no sistema escolar e nem nas mãos de educadores. Para a organização, uma abordagem em parceria seria necessária. De fato, quando observamos o contexto mundial, constatamos que o ensino do assunto se dá através de diversas organizações do setor privado e agências do governo, às vezes ligadas à educação e às vezes, não; como é o caso de quando se trata de bancos centrais, por exemplo.

Isto sugere uma diversidade de pontos de vista e de interesses sendo tratados sob o título de Educação Financeira. Como observou Mundy (2008), “algumas organizações do setor privado, como da área de serviços financeiros, fizeram da educação financeira um dos principais temas das suas atividades de responsabilidade social corporativa”. (MUNDY, 2008, p.65)

É claro que o raio de ação para se educar financeiramente a população é grande, mas acreditamos que a inserção do assunto na escola deveria estar nas mãos de especialistas em educação e dos diversos atores do sistema escolar.

No relatório encontramos uma preocupação com o monitoramento do financiamento privado e com o gerenciamento de possíveis conflitos de interesse entre as atividades comerciais de instituições financeiras e a educação financeira nas escolas. (cf. INFE/OECD, 2011). Mas achamos difícil que em alguns casos as duas coisas não estejam atreladas. Por exemplo, Mundy (2008), ao comentar sobre os cursos ministrados pelas instituições financeiras, comenta que essas instituições "lideram atividades relacionadas a bancos, seguros e conhecimento financeiro básico, além de 
oferecerem oportunidade aos estudantes de terem a experiência de abrir uma conta no banco". (MUNDY, 2008, p.65)

As diretrizes sugerem que professores estejam no centro do processo de introdução do assunto na escola visto que possuem experiência pedagógica e estreita relação com os alunos e que os principais objetivos de sua formação devam: i) abarcar a sensibilização sobre a importância de aprendizagem do assunto ao longo da vida e a disponibilização de métodos pedagógicos para a utilização de recursos didáticos disponíveis; ii) permitir que os discentes desenvolvam sua literacia financeira.

O relatório trouxe um anexo intitulado Draft Guidance Learning Frameworks on Financial Education $^{8}$, desenvolvido para fornecer, aos políticos e às partes interessadas, orientações mais detalhadas de como desenvolver um quadro de aprendizagem em seu país ou jurisdição. Sendo assim, ele é um complemento às diretrizes sobre Educação Financeira nas escolas, e seu propósito é apresentado nos seguintes termos:

\begin{abstract}
Quadro de aprendizagem sobre Educação Financeira é definido como uma abordagem planejada e coerente desta na educação formal em nível nacional e de outras jurisdições. Uma estrutura de aprendizagem de educação financeira deve operar em um meta-nível, proporcionando resultados educacionais no geral ou normas. $O$ quadro pode ser implementado em nível jurisdicional, escolar ou da sala de aula, na forma mais adequada para o contexto local. (INFE/OECD, 2011, p.16).
\end{abstract}

Assim o anexo apresenta os elementos constitutivos de um quadro de aprendizagem e sugestões para sua implementação nos países.

O único ponto que queremos destacar dessa parte do documento diz respeito às dimensões da literacia financeira, que os peritos da INFE sugerem como importantes que os estudantes desenvolvam em sua formação e que, portanto, deveriam ser cobertas por um programa de Educação Financeira. São elas: Conhecimento e compreensão; Habilidades e competências; Comportamentos; Atitudes e valores; Empreendimento. (OECD/INFE, 2011, p.16).

Muitos outros pontos foram discutidos no relatório, mas não é de nosso interesse tratá-los aqui. Observamos para efeito de informação, para concluir, que a meta da OCDE em seus estudos é prover os decisores políticos dos países membros de orientações e propostas de ações que possam ser colocadas em prática. Por isso, a preocupação com a avaliação é um dos aspectos centrais de sua maneira de operar. Por este motivo, sempre veremos, nos trabalhos da OCDE concretizados em seus documentos, a busca por entender o que é eficaz nos programas, o que vem dando certo e o que não tem funcionado bem.

\title{
Considerações Finais
}

\footnotetext{
${ }^{8}$ Em português: Orientação Preliminar sobre Quadros de Aprendizagem sobre Educação Financeira.
} 
A análise dos estudos e propostas da OCDE permitiu uma compreensão do cenário relativo à Educação Financeira dos cidadãos dos países analisados. O que percebemos foi que, em maior ou menor grau, as nações vivem ou se preparam para conviver com os problemas financeiros do nosso tempo que vão influenciar diretamente a vida das pessoas.

Neste cenário é fácil perceber que os governantes sabem que o ônus dessa conta, mantido o quadro atual, recairá sobre o Estado. Por outro lado, os estudos sugerem que uma população alfabetizada financeiramente reverte em ações positivas para o governo ao tomar decisões mais fundamentadas e ao exigir serviços de maior qualidade, estimulando a concorrência e a inovação do mercado. Essas pessoas, supostamente preparadas para tomar decisões nesse universo, seriam menos propensas a fazer reclamações infundadas e mais propensas a gerir riscos financeiros para elas transferidos. Além disso, seriam menos propensas a reagir de maneiras imprevisíveis às condições de mercado, além de não necessitarem da ajuda financeira do governo.

A partir da compreensão desse contexto, nosso interesse com a revisão da literatura foi entender a perspectiva da OCDE sobre o papel que a escola desempenharia em todo esse processo, em particular, nas características do ensino proposto pela organização.

Assim, nossa análise revelou que a importância de se ensinar Educação Financeira nas escolas possuía muitas vantagens explicitadas anteriormente no texto, entre elas, a possibilidade de se atingir um grande número de jovens e de poder influenciá-los desde cedo para terem hábitos saudáveis no uso do dinheiro.

Uma análise global da revisão da literatura sugere que as diversas questões e desafios apresentados pelos estudos da OCDE para o ambiente escolar são, de fato, as questões que deverão ser discutidas em qualquer proposta de inserção do assunto na escola.

A leitura das propostas da OCDE sugere que a concepção expressa nos documentos entende a Educação Financeira como sinônimo de educar os estudantes em finanças pessoais. Um exemplo dessa concepção pode ser identificado na proposta de avaliação em larga escala da organização, o PISA, cujo foco reside em avaliar literacia financeira pessoal, entendida nos seguintes termos: "A literacia financeira está preocupada com a forma como o indivíduo entende, gerencia e planeja as questões financeiras pessoais e de sua família. (OECD, 2012, p.14)

Apesar de alguns documentos da organização sugerirem que uma pessoa educada financeiramente tem impacto sobre a sociedade em geral, contribuindo para a estabilidade nacional e até mesmo mundial, fica visível que este não é o foco de sua proposta para o ensino na escola.

Sobre esta perspectiva, a questão que levantamos para pensar uma proposta futura de currículo é: no ambiente escolar, o ensino de educação financeira deverá ter como foco finanças pessoais ou haveria algo mais a tratar? 
A segunda característica que ressaltamos da proposta da OCDE sugere que a Educação Financeira deve preparar os estudantes para a vida adulta. Essa visão é claramente materializada na proposta de avaliação do PISA ao tentar avaliar, por exemplo, as concepções sobre situações bem específicas de um adolescente que se prepara para a vida adulta. Como consequência, um currículo elaborado sobre esta concepção deveria, obviamente, atender a essa demanda. (Cf. OECD, 2012, p.14)

Esta constatação nos remete a uma nova questão: um currículo de Educação Financeira para a escola deveria discutir temas tão específicos, ou deveria discutir temas mais gerais na direção de educar financeiramente os estudantes? Pois, ao focarmos em temas tão locais (no sentido cultural e geográfico), estaríamos supondo que todos os estudantes passariam pelos mesmos tipos de situações financeiras. Por outro lado, consideramos que seria impossível tratar todas as situações financeiras rotineiras que vivenciam os estudantes em sua formação em Educação Financeira.

Outra característica da proposta, que achamos bastante pertinente, é o entendimento de que Educação Financeira não se reduz à mera informação sobre finanças pessoais ou apenas ao domínio de um conteúdo curricular específico; seu ensino deveria, no entanto, envolver conhecimento financeiro, compreensão, habilidades, comportamentos, atitudes e valores.

Porém, esta característica leva a outra questão: é possível esperar que através do ensino escolar os estudantes desenvolvam habilidades, mudem comportamentos e atitudes em relação ao uso do dinheiro? Essa expectativa não poderia levar a uma proposta catequizadora de ensino de alguma perspectiva entendida como a correta em detrimento de outras perspectivas?

Outra característica identificada na proposta diz respeito aos atores envolvidos na inserção da Educação Financeira na escola. Na visão da OCDE, eles não são, necessariamente, os membros naturais desse meio, professores, por exemplo. Como vimos, os mais variados setores da sociedade são convidados a participar e, em muitos países, profissionais de instituições financeiras participam ativamente desse processo, formando os estudantes nas escolas.

Em resumo, com base em nossa pesquisa, consideramos que a proposta da OCDE de educar financeiramente a população terá resultados importantes para as nações e para o futuro dos estudantes, mas devemos investigar o que seria a formação desejável para ser introduzida na escola. Existem muitas questões que os profissionais do sistema escolar precisam discutir e decidir sobre elas.

Esse foi o ponto de partida em nossa investigação na compreensão de como poderemos introduzir a educação financeira na sala de aula de matemática na Educação Básica e de como a pesquisa em Educação Matemática pode participar desse processo de inserção. 


\section{Referências}

BRASIL. Plano diretor da ENEF: Estratégia Nacional de Educação Financeira (Anexos). 2011. Disponível em: www.vidaedinheiro.gov.br/docs/PlanoDiretorENEF1.pdf Acesso em novembro de 2011.

CNMV/BANCO DE ESPAÑA. Plan de Educación Financiera 2008-2012. Comission Nacional Del Mercado de Valores/CNMV y Banco de España. 2008. Disponível em: http://www.bde.es/webbde/es/secciones/prensa/EdU-Financiera-final.pdf Acesso em: agosto de 2011.

COMMONWEALTH BANK FOUNDATION. Improving financial literacy in Australia: benefits for the individual and the nation. Commonwealth Bank Foundation. 2004. Disponível em: $<$ http://www.commbank.com.au/about-us/download-printed-forms/FinancialLiteracyReport2004.pdf>. Acesso em dezembro de 2011.

EIOPA. Report on financial literacy and education initiatives by competent authorities. 2011. Disponível em https://eiopa.europa.eu/Publications/Reports/Report_on_Financial_Literacy_and_education_EIOPA -ccpfi-11-018.pdf . Acesso em março de 2012.

IMF - INTERNATIONAL MONETARY FUND. IMFSurvey, april, 2005.vol.34, nº 6 . Disponível em: www.imforg/external/pubs/ft/survey/2005/040405.pdf . Acesso em novembro de 2011.

WORD BANK. Measuring financial capability and the effectiveness of financial education. June 2012. Disponível em www-

wds.worldbank.org/external/default/WDSContentServer/WDSP/IB/2012/06/18/000333037_201206 18033233/Rendered/PDF/663900REPLACEM0t0Booklet015June2012.pdf. Acesso em setembro de 2012.

MUNDY, Shaun. Financial Education Programmes in school: Analysis of selected current programmes and literature draft Recommendations for best practices. OCDE journal: General papers, volume 2008/3. OCDE, 2008.

OECD. Improving Financial Literacy: Analysis of Issues and Policies. OECD, 2005a.

Disponível em: http://www.browse.oecdbookshop.org/oecd/pdfs/product/2105101e.pdf . Acesso em outubro de 2011.

OECD. Recommendation on Principles and Good Practices for Financial Education and Awareness. Directorade for Financial and Enterprice Affairs. Jul. 2005b. Disponível em $<$ http://www.oecd.org $>$ Acesso em outubro de 2011.

OECD/INFE. Guidelines on Financial Education at School and Guidance on Learning

Framework. OECD, 2011. Disponível em www.oecd.org/finance/financialeducation/48493142.pdf . Acesso em dezembro de 2011.

OECD. PISA 2012 Financial Literacy Assessment Framework. Paris: OECD, 2012. Disponível em: www.oecd.org/pisa/pisaproducts/46962580.pdf. Acesso em junho de 2012. 